\title{
La recuperación de los biografemas en el campo de los estudios biográficos: Barthes, Dosse y el devenir de un método inconcluso
}

\author{
The recovery of biographemes in biographical research: Barthes, Dosse and \\ the path of an inconclusive method \\ SERGIO MEIJIDE CASAS \\ Universidade de Santiago de Compostela \\ https://orcid.org/0000-0002-7605-4545 \\ sergio.meijide.casas@usc.es
}

\section{RESUMEN}

Aunque Roland Barthes ha sido generalmente presentado como aquel que puso fin a cierto interés por la autoría, sus escritos de comienzos de los años setenta problematizan su simple adscripción a la tesis de la muerte del autor, anticipando la vuelta a la biografía que tendría lugar posteriormente y que se extiende hasta nuestros días. El objetivo de este texto es recuperar sus reflexiones poco sistemáticas sobre los biografemas para explicar, por una parte, cómo han sido recibidas en el pensamiento de François Dosse, eminente teórico de la biografía y la historia cultural, así como en el quehacer de algunos otros biógrafos; y, por otra, cómo puede articularse tal concepto como una metodología que escape a la ficción textualista con la que habitualmente se ha asociado.

Palabras clave: Roland Barthes, François Dosse, biografía, biografemas, autor, fragmento, diferencia, texto, detalle.

\begin{abstract}
Although Roland Barthes has been generally introduced as the one who ended a certain interest in authorship, his writings from the early 1970s problematize his simple ascription to the 'death of the author' thesis, and that anticipates a return to the biography that would take place later and still endures to this day. The objective of this text is to recover his piecemeal reflections on biographemes in order to explain how they were received in François Dosse's thinking and some other biographers' endeavour. Furthermore, the aim of this text is to find out how this concept can be articulated as a methodology that escapes the textualist fiction that has often been associated with. Keywords: Roland Barthes, François Dosse, biography, biographems, author, fragment, difference, text, detail.
\end{abstract}




\begin{abstract}
«Porque si por una dialéctica retorcida debe haber en el Texto, destructor de todos los sujetos, un sujeto digno de amor, este sujeto está disperso, como las cenizas que se arrojan al viento tras la muerte (al tema de la urna y de la estela, objetos fuertes, cerrados, generadores de destino, se enfrentan las esquirlas del recuerdo, la erosión que sólo deja de la vida pasada algunos rasgos): si fuera escritor, y muerto, cómo me gustaría que mi vida se redujese, gracias a un biógrafo amistoso y sin prejuicios, a unos detalles, a unos gustos, a algunas inflexiones: podríamos decir «biografemas», cuya distinción y movilidad podrían viajar libres de cualquier destino y llegar, como los átomos epicúreos, a cualquier cuerpo futuro, condenado a la misma dispersión, una vida honrada en suma, como Proust supo escribir la suya en obra, o una película, al estilo antiguo, de la que está ausente toda palabra y en la que el chorro de imágenes (este flumen orationis en el que consiste seguramente la «suciedad» de la escritura) está entrecortado, como un hipo saludable, por el negro apenas apuntado de los rótulos, la irrupción descarada de un significante diferente: el manguito blanco de Sade, las macetas floridas de Fourier, los ojos españoles de Ignacio».
\end{abstract}

Roland Barthes (1997): Sade, Fourier, Loyola, 15-16. Traducción de Alicia Martorell del original de 1971.

\title{
1. INTRODUCCIÓN
}

Como explica François Dosse en su obra magna sobre la biografía, Le pari biographique. Écrire une vie (2007), el hecho de escribir una vida siempre ha estado atravesado por las imprecisiones propias de la novela. Por una parte, esto ha supuesto un abandono pleno de la pretensión de veracidad, ejercicio que ha terminado convirtiendo a algunos biógrafos en novelistas de pleno derecho, como ocurre en falsas biografías tan heterodoxas como la que hizo Antoine Billot sobre Wittgenstein ${ }^{1}$. Sin embargo, en muchas ocasiones se ha intentado hacer de este oficio una disciplina científica que encontrara una verdad causal en la infancia del biografiado. Esta segunda cuestión es especialmente evidente en las biografías de científicos y artistas, con anécdotas tan célebres como la del descubrimiento de Giotto por Cimabue (Vasari 1998 [1568]: 158) -en la que el segundo se sorprendió de las cualidades innatas que el primero tenía para la pintura naturalista-, cuyo objetivo no es otro que el de explicar cómo una obra no aparece por casualidad, e incluso cómo, cuando esta interviene, debe ser recogida por la genialidad de un sujeto paciente dispuesto a aprovecharla ${ }^{2}$.

Esta consideración inicial sobre la potencia creativa como una cuestión ya presente en la biografía fue continuada por reflexiones como la de Freud (1976 [1910]: 59-127)

1 En Le Désarroi de l'élève Wittgenstein (2003), su autor ficciona una supuesta amistad entre el filósofo Ludwig Wittgenstein y el dictador Adolf Hitler.

2 Sobre la cuestión de la «genialidad» se ha escrito mucho, pero si hay un libro que ha guiado nuestras reflexiones en la redacción es este texto, ese es The Possessor and the Possessed (Kivy, 2001). No obstante, frente a la dialéctica que él establece entre poseedor y poseído, apoyamos el hecho de que las casualidades deben ser recogidas para funcionar de forma efectiva, de ahí nuestra precisión al final del párrafo. 
desde el psicoanálisis, que encontró en la infancia de Leonardo da Vinci una conexión entre la sublimación libidinal y el instinto investigador, base de su quehacer artístico ${ }^{3}$. No obstante, estas propuestas tan deterministas sobre el devenir lineal del sujeto comenzaron a ser cuestionadas gracias a la recepción heideggeriana del pensamiento de Nietzsche y de Kierkegaard, que influyó de forma directa sobre tres de las corrientes filosóficas más importantes del pasado siglo: el existencialismo, el estructuralismo y el post-estructuralismo ${ }^{4}$. Con la primera, el individuo dejaba de ser una entidad completa y esencial para definirse como un sujeto existencial, heraclíteo, que se formaba a medida que vivía y decidía; con la segunda, el sujeto desaparecía -se tachaba, como llegó a afirmar Lacan- en favor de la estructura, siendo sustituida la intención con la que el biografiado había tomado sus decisiones por el texto, el subtexto y el contexto en el que estas se enmarcaran; y, por último, con la tercera se abandonó el estudio de las grandes estructuras para pensar la parte concreta que las habitaban, la diferencia que siempre fue inconmensurable al Todo que la cubría.

A través de esta sucesión de movimientos y corrientes de pensamiento, la investigación biográfica se vio totalmente trastocada: ya no se podía explicar una vida a partir de un sujeto-genio iluminado, sino a través de sus aciertos y sus errores (existencialismo), de sus textos y contextos (estructuralismo) y de sus multiplicidades (post-estructuralismo). Es por ello que la tarea de escribir una vida fue mutando. Así, el ejercicio realizado por Sartre (1947) en su biografía de Baudelaire, articulado sobre la noción de libertad, fue continuado por estudios muy diferentes como el llevado a cabo por Ginzburg (1976), dedicado a aquel pequeño molinero, heterodoxo y asistemático, cuya vida entera estaba dedicada a la diferencia.

Es en este contexto de crisis y transformación en las disciplinas humanísticas, concretamente en la transición entre el estructuralismo y el post-estructuralismo a finales de los años sesenta y principios de los setenta, donde aparece el concepto que nos ocupa: la noción de biografema, acuñada por el filósofo y semiólogo francés Roland Barthes. Aunque Barthes nunca ejerció de teórico de la biografía, sus reflexiones exceden el textualismo estructuralista al que habitualmente ha sido asociado, siendo enmarcado por

3 Como explica James Strachey (1976: 57), el escrito de Freud sobre la vida de Leonardo Da Vinci fue muy mal recibido, como tantas otras de sus publicaciones. A pesar de ello, hacemos referencia a él porque es indudable que la biografía y el psicoanálisis se han retroalimentado de una forma provechosa para ambos. Así, la aclaración que hace Freud al comienzo del capítulo seis de su texto (121), donde favorece la búsqueda de los defectos por encima del elogio de las virtudes, se ha establecido también como una de las bases de la investigación biográfica. Con nuestra propuesta biografemática nos sumamos al interés de Freud por la desmitificación de los grandes personajes, aunque no compartimos su excesiva preocupación por la causalidad monolítica.

4 Sabida la complejidad de las tres corrientes que aquí se cifran, así como la heterogeneidad de los teóricos que en ellas se enmarcan, no pretendemos otra cosa que trazar un mapa conceptual que ayude a comprender la razón y pertinencia del presente texto. En cualquier caso, para más información sobre el desarrollo histórico y conceptual de estas «escuelas de pensamiento»: Storia dell'esistenzialismo (Prini, 1989), Histoire du Structuralisme. Tomes 1 et 2 (Dosse, 1991-1992) y French Theory (Cusset, 2003). 
algunos teóricos en el ámbito del post-estructuralismo ${ }^{5}$. En cualquier caso, lo que nos interesa no son las categorías que legislan su pensamiento, sino este concepto que acuña en 1971 y que, sorprendentemente, nunca ha sido sistematizado teóricamente como una metodología operativa en el campo de la biografía, siendo aplicada de forma velada por algunos biógrafos que, en su búsqueda de la absoluta verosimilitud, no han aceptado una etiqueta ligada al devenir ficcional de la vida como relato.

Por todo ello, el objetivo del presente texto es recuperar la noción de biografema para ponerla al servicio de los nuevos estudios biográficos, aunque no como algo innovador, sino precisamente como una cuestión que ya está siendo aplicada pero que todavía no ha sido conceptualizada bajo tal etiqueta. Para ello, primero (apartado 2) explicaremos la aparición de tal cuestión en el período intermedio del pensamiento de Roland Barthes, centrándonos en sus textos comprendidos entre 1968 y 1975; en segundo lugar (apartado 3), trataremos su recepción en la obra de François Dosse, principal teórico de los estudios biográficos, explicando por qué el estudio de los biografemas nunca llegó a constituirse como una auténtica metodología; y, en tercer lugar (apartado 4), continuaremos las reflexiones de Dosse para profundizar en las pasadas y potenciales aplicaciones de tal concepto para la teoría y la práctica de la biografía, proponiendo algunas ideas para su posible sistematización metodológica.

\section{ROLAND BARTHES: EL AUTOR Y SUS CENIZAS}

En paralelo al progresivo cuestionamiento existencial del sujeto como entidad monolítica, los teóricos del New Criticism W. K. Wimsatt y Monroe Beardsley (1946) articularon una profunda reflexión sobre lo que llamaron intentional fallacy, según la cual el ejercicio de lectura siempre radicaría en una interpretación del texto, y no necesariamente de las intenciones que el autor depositó en él. Esta propuesta, cuyo marcado textualismo separaba el ejercicio productivo del creador y la recepción por parte del lector, favoreció el desarrollo de un conjunto de consideraciones posteriores que redujeron la importancia romántica otorgada a la subjetividad creadora, desplazando la preocupación del autor al contexto o al receptor. Algunas de las propuestas enmarcadas en esta deriva fueron la de Michel Foucault (1969) y la de Pierre Bourdieu (1986), pero, sin lugar a duda, la que mayor repercusión tuvo en los estudios biográficos fue la de Roland Barthes sobre la denominada «muerte del autor» ${ }^{6}$.

$5 \quad$ Es habitual que Critique et Vérité (Barthes, 1967) sea considerada, junto a Les Mots et les Choses (Foucault, 1966) y De la grammatologie (Derrida, 1967) como el origen de la french theory. Para algunos académicos, alguna de las tres obras ya se enmarcaría dentro de esta corriente; para otros, serían meros precedentes todavía enmarcados en el estructuralismo. Sobre el origen de esta etiqueta, así como los problemas asociados a esta, es especialmente interesante el estudio homónimo de François Cusset (2003). 
El texto de Barthes que da nombre a tal cuestión fue publicado originalmente en 1967 bajo el título «The Death of the Author» ${ }^{7}$, y lo más destacado del mismo fue su famosa reivindicación final del lector sobre el autor, o del lector como autor de su propia obra, libre del yugo interpretativo de aquel que la firmara. No obstante, pese a ser la emancipación del intérprete su consecuencia más famosa, el artículo comenzaba con otra pregunta: ¿quién es el que se esconde tras las palabras de Balzac? ¿El personaje de la novela, el propio Balzac o la psicología romántica? Ante la conclusión de que todo texto destruye su origen, la pregunta quedaba abierta, puesto que el «autor» nunca es la persona subyacente, sino la firma que ordena una obra que, en ocasiones, ha llegado a ser fruto de varias subjetividades claramente diferenciadas ${ }^{8}$.

Sin embargo, no podemos olvidar aquel famoso aserto atribuido a Flaubert: « $i$ Madame Bovary soy yo!». ¿Y Balzac? ¿No es también Balzac el personaje que él escribe? Si es así, la biografía es fundamental, pero: ¿y la psicología romántica? ¿No es también la psicología romántica el personaje que escribe Balzac? ¿Y no es el propio Balzac la psicología romántica? En ese caso, de ser el autor un mero mediador de tal psicología, la biografía no importaría demasiado: para entender las virtudes del texto habría que aproximarse al Romanticismo, no a la biografía. Sin embargo, la acuciante pregunta se mantiene: ¿por qué Balzac? Algo debía tener Balzac si su corpus autoral era tan bueno y sus textos tan agudos, se preguntaría Barthes, pues, ciertamente, la «muerte del autor» nunca pretendió anular los estudios biográficos y autorales, sino reformularlos. Al fin y al cabo, por habitar el Texto en todas las facetas de nuestra vida no debemos obviar la existencia del cuerpo.

Así, frente a la interpretación inicial de Barthes como asesino de autoridades, las investigaciones posteriores sobre su obra han problematizado su simple adscripción a esta tesis finalista, pues la «muerte del autor» no hizo otra cosa que acabar con el Autor para multiplicarlo en momentos y facetas: «autores», tantos como cenizas en una urna funeraria, tantos como momentos tiene una vida. Según Seán Burke (1992: 33), el autor estaría para Barthes «both dead and alive», pero precisamente lo que a nosotros nos interesa es la segunda parte, la vida del autor más allá de su anunciada muerte. No como figura de autoridad, sino como aquella multiplicidad creadora subyacente al texto, pues si Foucault y Bourdieu mantuvieron cierto estructuralismo en su análisis del sujeto, Barthes consiguió -en sus obras posteriores- reencauzar su perspectiva hacia las multiplicidades y diferencias que poblaron la filosofía francesa de los años setenta.

$7 \quad$ Frente a lo que ocasionalmente se tiene considerado, la traducción inglesa fue publicada antes que la versión original (Logie, 2013).

8 Nos referimos a aquellas firmas que, como el crimen de Fuenteovejuna, esconden una autoría múltiple. No obstante, si nos interesa destacar este fenómeno es para precisar que la autoría no deja de ser una forma de agrupar un conjunto de obras bajo una única firma, condición que, como ha comentado Luis G. Soto (2000), ha afectado al propio Barthes. Esto no se manifiesta únicamente en la publicación de sus obras completas, sino también en la cantidad de escritos biográficos sobre su persona (Culler, 1983; Calvet, 1990; Rylance, 1994; Marty, 2009; Gil, 2012; Samoyault, 2015; Sollers, 2015; Stafford, 2015). 
De entre todas las obras posteriores en las que se continuó preocupando por estas cuestiones, la primera en la que el discurso se abre a unas multiplicidades que consiguen desbordar el estructuralismo más rígido de S/Z (1970) es Sade, Fourier, Loyola (1971). En esta obra, Barthes aborda los textos biográficos o pseudo-biográficos de estos tres personajes para configurar un entramado que permite interconectarlos en sus diferencias, y es aquí donde acuña el concepto que nos ocupa. Lejos del estricto textualismo, su propuesta aborda la singularidad de los cuerpos, de los placeres y de los gustos, esquivando el retrato monolítico en favor de una deriva que reaviva la preocupación por el «bios» que está detrás de la palabra muerta. De hecho, como explica Dosse (2007 [2005]: 306-307), este bio-grafema conecta fuertemente con la muerte, pues evoca a aquel o a aquellos que ya no están mediante un detalle o fragmento que, en su particular diferencia, se desliga de la habitual imagen homogénea del sujeto.

Desde luego, en Sade, Fourier, Loyola no asistimos a un conjunto de escritos que podemos interpretar libremente, sino a una narración fragmentada que nos permite acercarnos a las diferentes vetas de cada uno de los tres implicados, evitando las tradicionales etiquetas que los han simplificado. De esta forma, es probable que sea cierto que la disciplina jesuita ha sido un obstáculo para leer los Ejercicios de Loyola, pues antes que «jesuita», su autor es Ignacio; e Ignacio es, a su vez, tantos como momentos. Borrar al autor es aplicar brocha gorda, embadurnarlo de pintura blanca, suprimirlo; pero Barthes está hilando muy fino, tejiendo milimétricamente las divergencias como un auténtico sastre de la diferencia. No está borrando a Loyola, sino atendiendo a sus fragmentos; no busca al «jesuita» ni al «militar», sino que se atiene al texto: deja que sea este quien le hable, como si del «verdear» heideggeriano se tratase. Es entonces cuando la palabra inerte -que solamente el lector puede vivificar- se manifiesta como vestigio de una vida, muchas vidas, tantas como biografemas. En términos derridianos, podríamos afirmar que tal ejercicio supone que el texto deje de ser producto causal del sujeto -la gran Vida- para configurarse como huella de un acontecimiento o conjunto de acontecimientos, de una identidad escindida que no puede no contradecirse consigo misma.

De la misma forma que apuntó Lavoisier en 1785, al señalar que «la materia no se crea ni se destruye: solo se transforma ${ }^{9}$, la propuesta de Barthes se articularía sobre el «resto» del autor, los fragmentos rotos y abandonados de la gran figura. Es a partir de ellas que piensa una nueva forma de afrontar la vida y la autoría, no como un todo cerrado, sino como un conjunto de pedazos miniaturizados, pues solo de esta forma podían conjugarse Balzac, su personaje y la psicología romántica. Desde luego, no existe únicamente el autor-genio, ni el autor-firma, ni el autor-cuerpo, sino todos ellos. El biografema no contradice la biografía, ni la muerte del autor acaba con ella, como tampoco lo hicieron las propuestas de Foucault y Bourdieu. Así lo explica el propio Barthes al señalar lo siguiente:

9 La famosa frase remite a su Traité Élémentaire de Chimie (1789), pero nunca fue enunciada por él como tal, sino que es producto de la simplificación de su contenido. 
$\mathrm{El}$ autor que vuelve no es evidentemente el que han identificado nuestras instituciones (historia y enseñanza de la literatura, de la filosofía, discurso de la Iglesia); tampoco es el protagonista de la biografía. El autor que viene de su texto y va a nuestra vida no tiene unidad; es un simple plural de "encantos", el soporte de algunos detalles tenues, fuente de una fuerte luz novelesca, un canto discontinuo de amenidades en el que leemos la muerte con más seguridad que en la epopeya de un destino; no es una persona (civil, moral), es un cuerpo.

(Barthes 1997 [1971]: 14-15)

El primer momento de la «revolución» de Barthes fue destructor, incluso liberador: mató al autor para darnos vida a los lectores, para que pudiésemos estudiar y disfrutar el texto con la libertad de aquel que no está de acuerdo con la interpretación que el autor hizo del mismo. El segundo momento fue el organizador: recogió las cenizas del asesinado y nos las entregó a los lectores, para que viésemos que el autor no era uno, sino varios, y que leer la obra contra el Autor es afirmar una otra autoría, desprejuiciada, pero igualmente autoría; pues, en efecto, todo estaba en el texto. El ejercicio es semejante al que Lyotard (1979) articula al fragmentar aquellos métarécits en una multiplicidad de cuasiinfinitos petits récits, múltiples y contradictorios; pero, en este caso, la miniaturización se da dentro del corpus autoral y biográfico.

Este regreso del autor que se produce en la obra de Barthes no queda únicamente limitado a Sade, Fourier, Loyola, sino que tiene una continuidad clara en sus siguientes obras, como Le Plaisir du texte (1973) y Roland Barthes par Roland Barthes (1975), pero también en algunos de los seminarios que impartió durante esos años, llegando a aparecer la noción de biografema en su última obra La Chambre Claire (1980). En este texto, el detalle del biografema tiene su continuidad en el punctum, relación que él mismo advierte y que conecta igualmente con la memoria; pero no es este el período que nos interesa explorar, pues el concepto queda plenamente desarrollado en el período articulador de su autobiografía, esto es, el comprendido entre la publicación de Sade, Fourier, Loyola y Roland Barthes par Roland Barthes.

En Le Plaisir du texte, la manifestación del biografema se produce mediante la implicación de ese cuerpo detrás del texto, un autor que produce su obra en el placer. «Si leo con placer esta frase, esta historia o esta palabra es porque han sido escritas en el placer (este placer no está en contradicción con las quejas del escritor)», dice, pero «¿Escribir en el placer, me asegura a mí, escritor, la existencia del placer de mi lector? De ninguna manera» (Barthes, 1993 [1973]: 12). El argumento, no exento de polémica, alude al tema que aquí nos ocupa: el texto que permite una lectura placentera siempre remite a una producción placentera; que no es sino biografemática. Yendo incluso contra el propio Barthes y afirmando el displacer, este resultaría igualmente en detalle biográfico

Por otra parte, en Roland Barthes par Roland Barthes es el propio autor, expulsado de sí mismo, el que se reconoce como un cuerpo otro, personaje ficcional de una novela, que no deja de ser mismo en tanto que produce de forma placentera. Pero aquí ya no 
entra solo la recepción, sino que es el propio fragmento en su manifestación autónoma el que se manifiesta como texto y como imagen. Como dice Robin (1998: 6), es «un libro escrito contra todo aquello que detiene el devenir existencial haciéndolo encajar en una identidad» ${ }^{10}$.

Sin embargo, la evidencia más clara de la articulación teórica de la noción de biografema se encuentra en los seminarios que preparó durante esos años. Mientras que Sade, Fourier, Loyola no es un texto dedicado a desarrollar la noción de biografema, pues esta sirve más bien de concepto paraguas para agrupar una serie de escritos que ya fueran publicados previamente, algunas de estas clases completan la información perdida sobre un concepto que viajó - de forma velada- junto a Barthes hasta su fallecimiento.

De esta manera, el seminario «10 años de semiología. La teoría del texto (19711972)» se aproxima al quehacer biografemático en tanto que nexo entre diferentes subjetividades. De la misma forma que había conectado en Sade, Fourier, Loyola su propia biografía con la de Sade, al mencionar que este fue arrestado en el mismo lugar donde se editó el libro de Barthes, o las vidas de Fourier y Sade al revelar al primero como lector del segundo, en este curso aborda el trabajo de diferentes teóricos a partir de su vivencia como lector de sus obras. Aquí encontramos una primera articulación de lo expresado en su libro, pero no será hasta los seminarios de 1974 cuando termine de definir lo que suponen los biografemas, ya como antesala de la aplicación que hará de los mismos en su autobiografía. Así, tanto en Le lexique de l'auteur (2010), texto derivado de su seminario de 1974-1975, como en el «taller de biografemática» que desarrolló en paralelo, se muestra que el rasgo significante in-significante se manifiesta en aquella contradicción que permite que el autor sea revivido por el lector como cuerpo (Amigo Pino y Amaro, 2018: 167-171).

Frente a las aproximaciones tradicionales al concepto, lo que revelan los apuntes de Claudia Amigo y Lorena Amaro sobre las anotaciones de João Batista Natali, discípulo de Barthes, es una primacía de la contradicción como vía desarticuladora de aquello que fuera un único Autor y, gracias a los biografemas, deviene en subjetividad escindida. No obstante, aún insistiendo en la primacía de lo fragmentario, del significante diferente e insignificante, los estudios biográficos no han terminado de aprovechar las posibilidades de estudiar los tiempos muertos, siendo comúnmente acusadas las aproximaciones tan parciales de falta de rigurosidad.

\section{FRANÇOIS DOSSE: EL BIOGRAFEMA COMO FICCIÓN}

Como afirmó el famoso biógrafo André Maurois (1932: 70): «Los detalles pequeños son, a menudo, los más interesantes». No obstante, el gusto de los biógrafos por las rarezas, los encuentros, las reacciones y las particularidades del sujeto biografiado fueron

10 Traducción del autor. 
utilizados comúnmente como «gancho» para conectar con el lector, adscribiéndose a la deriva novelística del género y no a la búsqueda del fragmento como verdadera fuente de información (Dosse, 2007 [2005]: 55-59). Así, estas anécdotas permitieron reforzar ideas de la gran biografía o, por el contrario, favorecer pequeñas discordancias pintorescas acordes al desarrollo del personaje y no de la propia persona, alimentando la mitología del biografiado. Un ejemplo de esta cuestión sería la anécdota que cuenta cómo Kant, el caminante más sistemático de la Historia de la Filosofía, renunció a su paseo diario por leer el Emilio de Rousseau, un detalle que, independientemente de su veracidad, enriquece sus matices como personaje de ficción ${ }^{11}$.

Por su uso y abuso, el estudio micrológico de las vidas ha sido tratado durante mucho tiempo como una cuestión ligada a cierto periodismo sensacionalista, más preocupado por los «líos de faldas» que por los profundos conceptos subyacentes a las fascinantes vidas de los biografiados. Así se explica que el concepto de «biografema» no haya tenido una articulación metodológica digna de sus posibilidades y que, aun siendo recogido por el exhaustivo estudio de Dosse (2007 [2005]), sea tachado como si de una propuesta ineficiente se tratase. No obstante, debemos detenernos en la recepción que el biógrafo e historiador francés ha hecho de esta cuestión para comprender las imposibilidades que detecta en su aplicación práctica.

En el libro de Dosse, la estructura del índice ya revela una compartimentación semejante a la utilizada por nosotros al comienzo de este escrito, transitando en sus últimos capítulos desde la biografía existencialista a las multiplicidades del post-estructuralismo, evolución que enmarca en lo que denomina «edad hermenéutica». Sin embargo, la de los biografemas es la única deriva presente en su obra que verdaderamente se aproxima a uno de los asertos más radicales del pensamiento francés post-sesentayochista, aquella máxima de Deleuze y Guattari (1980: 9) que aseguraba que cada uno de nosotros somos varios. Aunque es inevitable que aquel que fuera biógrafo croisée de ambos no pudiera evitar el dejarse iluminar por sus reflexiones, llama la atención que el único apunte que refiere a la multiplicidad interna al sujeto social -en la totalidad de la obra- sea el de los biografemas. Así, los otros apartados de ese quinto capítulo dedicado a la pluralidad de las identidades remiten a pensamientos más rentabilizados desde la teoría de la biografía, como la microhistoria («El hombre común»), la nueva biografía política («La construcción de identidades políticas»), la biografía psicoanalítica («Psicohistoria y biografías psicoanalíticas») y la biografía hermenéutica («Las metamorfosis de la identidad narrativa»).

Sin embargo, lo más interesante de esta cuestión no es que únicamente se adscriba a la multiplicidad del sujeto con la defensa del biografema, sino que, de hecho, tal cuestión nunca llega a producirse. Aunque rescata el interés del concepto, intrínsecamente ligado

11 Este detalle biográfico ha sido ampliamente divulgado a lo largo de la historia, llegando incluso a nuestro tiempo. No obstante, el historiador de la filosofía Manfred Kuehn ha apuntado que es muy probable que esta anécdota sea falsa (2001: 458, nota 153). 
a la ocupación biográfica como algo más que un mero juego textual, nunca abandona sus sospechas sobre las posibilidades que subyacen a tal propuesta, llegando a afirmar que estos biografemas «dejan al lector en lo indecible y lo incierto» (Dosse, 2007 [2005]: 6970). Desde luego, el origen de su sospecha no es baladí, pues ya el propio Barthes había afirmado en el número 47 de la revista Tel Quel, el mismo año de publicación de Sade, Fourier, Loyola (1971), que «toda biografía es una novela que no osa decir su nombre» (Dosse, 2007 [2005]: 307).

Como ya anunciamos al comienzo del artículo, la relación entre la novela y la biografía es una de las principales tensiones que recorren el estudio de Dosse, en donde constantemente recuerda que no se debe renunciar al estilo para ser preciso. Esto habría que completarlo con la puesta en relieve de que lo que debería procurar un biógrafo riguroso -que se sepa a sí mismo diferente a un novelista- es combatir el mito, puesto que, frente a la ya mentada Historia «científica», la vida siempre está atravesada por el error y la casualidad.

Aquí aparece la virtud de los biografemas, pues si no hay Vida, sino vidas, no hay Obra, sino obras, y no hay Autor, sino autores; no hay mito posible. Descomponer y fragmentar la Vida de(con)struye la necesidad orgánica que rige cualquier estructura, liberando cada una de las partes de la pieza que las aúna. No obstante, ¿ahondar en esos detalles no implica profundizar en los tiempos muertos -y desconocidos- de los que, a diferencia de la vida pública, no hay documentación? A fin de cuentas, Sade, Fourier, Loyola no es un texto biográfico, y en Roland Barthes par Roland Barthes estamos a expensas de la producción autopoiética que acomete el propio biógrafo, que es también el biografiado. ¿Son entonces los biografemas un producto de ficción?

Para entender esta cuestión, debemos detenernos en cómo empieza y cómo termina el libro de Dosse. «Escribir la vida sigue siendo una esfera inaccesible y, sin embargo, sigue siempre impulsando el deseo de narrar, de comprender» (11), señala al comienzo, concluyendo finalmente con la sentencia de que «en su edad hermenéutica, la biografía ya no tiene la ilusión de enunciar la realidad y de saturar el sentido» (412). ¿Descarta Dosse la rigurosidad de su aproximación? No, evidencia la imposibilidad de asir aquello que no puede ser conocido. Sin embargo, no renuncia a la rigurosidad. Todos aquellos que hemos leído sus textos conocemos de primera mano que Dosse no produce fantasías, sino que, contrariamente, aplica diferentes metodologías desde el conocimiento pleno de lo que implica narrar lo inenarrable, aquellas vivencias para las que todo papel resulta insuficiente.

Frente a la mesura con aquello documentado, Barthes sería un novelista que ha renunciado a hacerse pasar por «hombre de ciencia» (306). Pese a todo, un biografema no es un mero invento, o, al menos, no tiene por qué serlo. Al igual que la biografía nació como algo próximo a la ficción y se desarrolló históricamente como tal, los biografemas pueden aplicarse con la rigurosidad de Dosse, libres de la supuesta ficcionalización que se achaca a aquel que fuera su creador. Su fundamento no está en la invención o reconstrucción de momentos vividos, sino en su atomización, su pluralización y su descomposición. 
Si la biografía resulta y ha resultado una herramienta peligrosa para la investigación histórica, esto es así por el afán de totalidad que favorece la psicologización de los momentos sobre los que no hay datos rescatables. No obstante, más allá de las herramientas propias del escritor para captar el interés de sus lectores, como la invención de anécdotas y situaciones, es en muchas ocasiones la falta de información la que obliga al biógrafo a proceder como escritor de ficción, algo a lo que el propio Dosse alude de la siguiente manera:

La otra gran contradicción de la que la mayor parte de los biógrafos ni siquiera parecen ser conscientes reside en el hecho de que querer escribir la vida de un individuo presupone un dominio y una visión totalizadora de lo que ha sido a lo largo de su vida. «Ahora bien, los textos de biógrafos, aunque están muy bien "acabados" con relación a su discurso, presentan grandes lagunas en lo relativo a la información» ${ }^{12}$. Lo que explica la técnica del espesante, que utiliza la psicología para rellenar los huecos y cuajar la salsa biográfica creando la ilusión de que se ha reconstruido la totalidad de una persona.

(Dosse, 2007 [2005]: 95)

Los biografemas permiten evitar este escollo, pues, a diferencia de la biografía tradicional, no obligan a cubrir los huecos. Cuando el biógrafo se centra en el fragmento, no hay un «todo» al que deba dar forma, pudiendo callar sobre aquello que desconoce. No es, por tanto, una metodología amparada en la deriva más literaria -y menos histórica- del género, sino una aproximación más libre a la vida o vidas del biografiado. Así, no solo resulta ser un procedimiento riguroso, sino que también permite desarrollar la veta más creativa del investigador, pues el fragmento es libremente combinable y, como el aforismo, no debe rendir cuentas al conjunto del texto, algo con lo que Dosse, defensor de la buena escritura, debería estar de acuerdo. ¿Cuál es, entonces, su diferencia con la tarea habitual del proceso de escribir una vida? Que frente al estudio del todo, aquí se prima la parte; pero no necesariamente como una ficción dentro del Texto, aunque Barthes así lo concibiera y Dosse así lo perpetuara.

\section{HACIA UNA METODOLOGÍA FRAGMENTARIA}

A pesar de que Barthes nunca articuló los biografemas como una propuesta metodológica para la renovación de los estudios biográficos, y conociendo que estos fueron posteriormente menospreciados por Dosse -quien, como hemos visto, los incluyó en su estudio histórico y conceptual de la biografía, pero los enmarcó en el ámbito de la ficción-, es indudable que el fragmento biográfico ha sido aprovechado recientemente como uno de los fundamentos del proceso de escritura de una vida. De esta forma, aun sin apelar

12 La cita introducida por Dosse corresponde a Philippe Lejeune (1980): J'est un autre, París: Seuil, 77-78. 
a esta etiqueta, muchas de las revisiones biográficas más recientes, como la que Isabelle Mons hizo de la de Lou Andreas-Salomé (2012), o la que Kiff Bamford hizo de la vida de Jean-François Lyotard (2017), apelan al detalle como clave articuladora de un relato que se ve fortificado por la humanización del personaje en sus contradicciones. Esta metodología ya había sido utilizada por Dosse en muchas de sus biografías, pero nunca bajo la autoconsciencia de estar rastreando arqueológicamente momentos biografemáticos, pues, estando esta etiqueta ligada convencionalmente a la ficción, se olvidó aquello que Barthes puso en lo alto del podio, «la irrupción descarada de un significante diferente» (Barthes 1997 [1971]: 15-16), un detalle que trastoca el Todo homogéneo de la vida en favor de la divergencia que fragmenta al sujeto ${ }^{13}$.

Si leemos a Barthes como él mismo propuso abordar la lectura -dando vida al lector- y tomamos los biografemas como detalles móviles que pueden «viajar libres de cualquier destino y llegar, como los átomos epicúreos, a cualquier cuerpo futuro, condenado a la misma dispersión» (Ídem), resulta inevitable pensar que las posibilidades de su propuesta deben exceder los límites que él mismo puede haber encontrado en ella. Es únicamente así que podemos articular el estudio de los biografemas como algo más que un arte memorial, llegando a definir su búsqueda como una metodología de pleno derecho, pero para ello debemos acercarnos a cada una de las formulaciones de la misma idea que fue tejiendo Barthes en su producción literaria de los años setenta.

Por una parte, en Sade, Fourier, Loyola el acento no está puesto únicamente en el detalle, sino en la recepción del mismo, en tanto que fragmento que viaja libre y es recibido; por otra, en el caso de Le Plaisir du texte tenemos al lector que goza de la lectura pero también al escritor-cuerpo al que le place la escritura; y, por último, en Roland Barthes par Roland Barthes tenemos la imagen marginal que, como el punctum, apela de una forma específica al receptor, multiplicando la consideración que se tiene de la figura encarnada por el Autor. En los tres casos el concepto es el mismo, pero abordado de forma diferente, pues toda producción textual viaja libre y se activa al ser recibida; todo creador es cuerpo en el momento de producir, sea o no esta producción algo placentero; y todo fragmento insignificante ejerce de significante diferente al favorecer la discordancia con la homogeneidad del sujeto. En los tres casos, y en concordancia con los demás textos en los que el concepto se manifiesta, incluidos los seminarios, encontramos que el fragmento se transmite textualmente y apela a una diferencia con respecto a la tradicional figura del sujeto-creador.

¿Por qué no va a configurarse esta propuesta como una metodología válida? Siempre que entendamos que el devenir ficcional del biografema puede suponer un sujeto igualmente ficcional, podemos aprovechar la independencia creativa del fragmento para

13 La aplicación del fragmento biografemático también ha encontrado acogida en otros ámbitos diferentes al de la biografía. Un ejemplo de ello es el libro Micrologías (2012) de Federico L. Silvestre, donde no solo se hace un fragmentado repaso histórico por ese interés por lo pequeño, sino también una proyección de tal fascinación hasta nuestro presente inmediato. 
abordar la multiplicidad de la vida desde el rigor que caracteriza la práctica del historiador, recogiendo la información dispersa y contradictoria presente en los documentos y los archivos para transportarla libremente hacia el lector, haciéndole entender que el cuerpo presente tras el texto es múltiple y abierto.

No obstante, como ya comentamos, esta no es una cuestión nueva. Aunque nuestra propuesta radique en el tratamiento desprejuiciado - por parte del biógrafo- de la información que tenga disponible, las biografías más ortodoxas siempre estuvieron llenas de curiosos biografemas que constantemente multiplicaron la imagen habitual del biografiado. Un ejemplo de ello es el escrito que dedicó Conquest al polémico estadista Iósif Stalin, gran amante -según Jruschov- de John Wayne y los westerns norteamericanos (1991: 282). De hecho, incluso el propio Vasari recurre al biografema cuando aborda vidas como la de Uccello, del que cuenta anécdotas tales como su abandono temporal de un trabajo donde solamente le daban queso por comida, su reclusión permanente ante un comentario mal recibido de Donatello o su preferencia de pintar «dulcemente» la perspectiva en lugar de ir a acostarse junto a su mujer (1998 [1568]: 183-186). Ahí están los biografemas, una vida reducida a unos pequeños detalles y gustos, placenteros o displacenteros, que dan cuenta del cuerpo del que crea, piensa o disfruta. Puede que la atención a tal asunto no resulte una cuestión moderna o posmoderna, ni tan siquiera un problema hermenéutico, sino que precisamente radique en la preocupación por la propia vida, aquello que en su origen dio pie a la biografía y que Barthes hizo bien en denominar biografema.

\section{CONCLUSIÓN: UN CUERPO DETRÁS DEL TEXTO}

La propuesta que ha guiado la elaboración de este texto ha sido la de recuperar un concepto que nos permita acercarnos al estudio de la biografía desde una perspectiva diferente, como un fragmento viajero que puede ser separado del todo de la vida. Lo interesante de esta cuestión no es únicamente el hecho de que tal metodología ya hubiera sido aplicada de forma no sistemática, sino que, precisamente, nos permite rescatar a un Barthes diferente al habitual. Desde luego, su capacidad para captar el fragmento en el devenir biográfico del texto conecta más con la articulación del punctum de sus últimos escritos que con el estructuralismo radical de finales de los años sesenta, algo que, sin ser una aportación novedosa de este artículo, refuerza la posible ubicación de estas reflexiones entre las nuevas metodologías para el estudio de la biografía, aquellas derivadas de la perspectiva abierta por el post-estructualismo.

Así, hemos intentado utilizar al pequeño Barthes contra el grande, remando con la vida contra el texto, con el placer de la lectura y la escritura contra la palabra inerte y apolillada. No obstante, nuestra mayor preocupación es severa, pues seguimos presos del devenir causal. La muerte del autor devolvió la vida al texto, pero su resurrección parece que ha vuelto a acabar con él. En el mundo académico, la gran Vida inmóvil se ha comido a la pequeña vida que corretea, y el desilusionante presente biográfico anunciado por 
Dosse no ha sido contrarrestado por un verdadero resurgimiento de aquella preocupación que lo rondaba: «escribir una vida». Mientras el horizonte de la ficción biográfica avanza a una velocidad pasmosa, con miles de los mejores escritores y cineastas de nuestro tiempo implicados en la tarea, el estudio «riguroso» de la biografía no ha sabido acercarse al retazo como corresponde. Puede que sigamos pensando que ciertas imágenes pertenecen exclusivamente a los escritores, imaginadores de mundos posibles que sí son capaces de abordar el detalle; pero también desde los estudios académicos deberíamos buscarlo, con textos, documentos y entrevistas, vaciando archivos y bibliotecas, o como corresponda a nuestras respectivas tareas. Lo que Barthes quería decirnos es que el fragmento experiencial es lo importante, y nosotros, al tacharle de novelista, se lo hemos regalado a otros. Como estudiosos del pensamiento estético, de la labor histórica o artística y del hacer biográfico, es momento de recuperar lo que nos fue legado, pues pensar la vida no es pensar el texto, sino entender que detrás de este siempre hay un cuerpo. 


\section{BIBLIOGRAFÍA}

Amigo Pino, C. y Amaro L. (2018): «Del biografema a la comunidad: dos casos recientes en la literatura latinoamericana», Alea, XX, 2, pp. 165-183.

Bamford, K. (2017): Jean-François Lyotard, Londres: Reaktion.

Barthes, R. (2010): Le lexique de l'auteur, París: Seuil.

Barthes, R. (1997): Sade, Fourier, Loyola, trad. A. Martorell, Madrid: Cátedra [1971].

Barthes, R. (1993): El placer del texto, trad. N. Rosa, México: Siglo XXI [1973].

Barthes, R. (1980): La Chambre Claire, París: Gallimard.

Barthes, R. (1977): «The Death of the Author», en S. Heath (ed.), Image, Music, Text, trad. R. Howard, Londres: Fontana, pp. 142-148 [1967].

Barthes, R. (1975): Roland Barthes par Roland Barthes, París: Éditions du Seuil.

Barthes, R. (1970): S/Z, París: Éditions du Seuil.

Barthes, R. (1966): Critique et Vérité, París: Éditions du Seuil.

Billot, A. (2003): Le Désarroi de l'élève Wittgenstein, París: Gallimard.

Bourdieu, P. (1986): «L'illusion biographique», Actes de la Recherche en Sciences Sociales, 62-63, pp. 69-72.

Burke, S. (1992): The Death and Return of the Author: Criticism and Subjectivity in Barthes, Foucault and Derrida, Edimburgo: Edinburgh University Press.

Calvet, L.-J. (1990): Roland Barthes: 1915-1980, Bloomington: Indiana University Press.

Campillo, A. (1992): «El autor, la ficción, la verdad», Daimon, 5, pp. 25-45.

Conquest, R. (1991): Stalin: Breaker of Nations, Nueva York: Viking Penguin.

Culler, J. (1983): Roland Barthes, Oxford: Oxford University Press.

Cusset, F. (2003): French Theory. Foucault, Derrida, Deleuze et Cie et les mutations de la vie intellectuelle aux États-Unis, París: La Découverte.

Deleuze, G. y Guattari, F. (1980): Mille plateaux, París: Éditions de Minuit.

Derrida, J. (1967): De la grammatologie, París: Éditions de Minuit.

Dosse, F. (2007): La apuesta biográfica. Escribir una vida, trads. J. Aguado y C. Miñana, Valencia: Publicacions de la Universitat de València [2005].

Dosse, F. (1992): Histoire du Structuralisme. Tome 2: Le chant du cygne, 1967 à nos jours, París: La Découverte.

Dosse, F. (1991): Histoire du Structuralisme. Tome 1: Le champ du signe, 1945-1966, París: La Découverte.

Foucault, M. (1969): «Qu'est-ce qu'un auteur?», Bulletin de la Société Française de Philosophie, LXIII, 3, pp. 73-103.

Foucault, M. (1966): Les Mots et les Choses, París: Gallimard.

Freud, S. (1976): «Recuerdo infantil de Leonardo da Vinci», en J. Strachey (ed.), Sigmund Freud. Obras Completas XI, trad. J. L. Etcheverry, Buenos Aires: Amorrortu, pp. 53-129 [1910].

Gil, M. (2012): Roland Barthes : Au lieu de la vie, París: Flammarion.

Ginzburg, C. (1976): Il formaggio e i vermi. Il cosmo di un mugnaio del '500, Turín: Einaudi. 
Kivy, P. (2001) The Possessor and the Possessed. Handel, Mozart, Beethoven, and the Idea of Musical Genius, New Haven: Yale University Press.

Kuehn, M. (2001): Kant. A Biography, Cambridge: Cambridge University Press.

Lavoisier, A.-L. (1789): Traité Élémentaire de Chimie, París: Chez Cuchet.

Lejeune, P. (1980): J'est un autre, París: Seuil.

Logie, J. (2013): «1967: The Birth of "The Death of the Author"», College English, LXXV, 5, pp. 493-512.

López Silvestre, F. (2012): Micrologías. O historia breve de las artes mínimas, Madrid: Abada.

Lyotard, J.-F. (1979): La condition postmoderne : rapport sur le savoir, París: Éditions de Minuit.

Marty, E. (2009): Roland Barthes: Le Metier d'écrire, París: Seuil.

Maurois, A. (1932): Aspects de la biographie, París: Grasset.

Mons, I. (2012): Lou Andreas-Salomé : En toute liberté, París: Perrin.

Prini, P. (1989): Storia dell'esistenzialismo: Da Kierkegaard a oggi, Roma: Studium.

Robin, R. (1998): «Point de vue: L'autofiction», CV Photo, 44, pp. 5-6.

Rylance, R. (1994): Roland Barthes, Londres: Harvester Wheatsheaf.

Samoyault, T. (2015): Barthes: A Biography, París: Seuil.

Sánchez Trigueros, A. (2013): El concepto de sujeto literario y otros ensayos críticos, Madrid: Biblioteca Nueva.

Sartre, J.-P. (1947): Baudelaire, París: Gallimard.

Sollers, P. (2015): L'Amitié de Roland Barthes, París: Seuil.

Soto, L. (2000): «Barthes al completo», Daimon, 20, pp. 181-186.

Stafford, A. (2015): Roland Barthes, Londres: Reaktion.

Vasari, G. (1998): Las vidas de los más excelentes arquitectos, pintores y escultores italianos desde Cimabue a nuestros tiempos (Antología), trads. M. T. Méndez Baiges y J. M. Montijano García, Madrid: Tecnos [1568].

Wimsatt, W. K. y Beardsley, M. (1946): «The Intentional Fallacy», The Seweanee Review, CIV, 3, pp. 468-488. 